\title{
Selection and optimization of pure and mixed working fluids for low grade heat utilization using organic Rankine cycles
}

Andreasen, Jesper Graa; Larsen, Ulrik; Knudsen, Thomas; Pierobon, Leonardo; Haglind, Fredrik

Published in:

Energy

Link to article, DOI:

10.1016/j.energy.2014.06.012

Publication date:

2014

Document Version

Early version, also known as pre-print

Link back to DTU Orbit

Citation (APA):

Andreasen, J. G., Larsen, U., Knudsen, T., Pierobon, L., \& Haglind, F. (2014). Selection and optimization of pure and mixed working fluids for low grade heat utilization using organic Rankine cycles. Energy, 73, 204-213. https://doi.org/10.1016/j.energy.2014.06.012

\section{General rights}

Copyright and moral rights for the publications made accessible in the public portal are retained by the authors and/or other copyright owners and it is a condition of accessing publications that users recognise and abide by the legal requirements associated with these rights.

- Users may download and print one copy of any publication from the public portal for the purpose of private study or research.

- You may not further distribute the material or use it for any profit-making activity or commercial gain

- You may freely distribute the URL identifying the publication in the public portal 


\title{
Selection and optimization of pure and mixed working fluids for low grade heat utilization using organic Rankine cycles
}

\author{
J.G. Andreasen*, U. Larsen, T. Knudsen, L. Pierobon, F. Haglind \\ Technical University of Denmark, Department of Mechanical Engineering Building 403, Nils Koppels Allé, \\ DK-2800 Kgs. Lyngby, Denmark
}

\begin{abstract}
We present a generic methodology for organic Rankine cycle optimization, where the working fluid is included as an optimization parameter, in order to maximize the net power output of the cycle. The method is applied on two optimization cases with hot fluid inlet temperatures at $120^{\circ} \mathrm{C}$ and $90^{\circ} \mathrm{C}$. Pure fluids and mixtures are compared to see how mixed working fluids affect performance and important design parameters. The results indicate that mixed working fluids can increase the net power output of the cycle, while reducing the pressure levels. The maximum net power output is obtained by fluids with a critical temperature close to half of the hot fluid inlet temperature. For some mixtures we find the maximum net power when the temperature glide of condensation matches the temperature increase of the cooling water, while for other mixtures there are large differences between these two parameters. Ethane is a fluid that obtains a large net power increase when used in mixtures. Compared to pure ethane, an optimized ethane/propane mixture attains a $12.9 \%$ net power increase when the hot fluid inlet temperature is $120^{\circ} \mathrm{C}$ and a $11.1 \%$ net power increase when the hot fluid inlet temperature is $90^{\circ} \mathrm{C}$.
\end{abstract}

Keywords: organic Rankine cycle, genetic algorithm, fluid selection, zeotropic mixtures, low grade heat, geothermal

\section{Introduction}

The organic Rankine cycle (ORC) is a technology, that can produce mechanical power from various heat sources. Compared to the traditional steam Rankine cycle the ORC has

\footnotetext{
${ }^{*}$ Corresponding author. Tel.: +45 45 254123

Email address: jgan@mek.dtu.dk (J.G. Andreasen)
} 


\begin{tabular}{|c|c|c|c|}
\hline \multicolumn{2}{|l|}{ Acronyms } & \multicolumn{2}{|c|}{ Subscripts and superscripts } \\
\hline GWP & Global warming potential & boil & Boiling \\
\hline HMIS & Hazardous Materials Identification System & cond & Condenser \\
\hline ODP & Ozone depletion potential & cool & Cooling water \\
\hline ORC & Organic Rankine cycle & $\exp$ & Expander \\
\hline & & g & Glide of condensation \\
\hline Greek symbols & & hf & Hot fluid \\
\hline$\Delta$ & Difference & $\mathrm{I}$ & First law/thermal \\
\hline$\epsilon$ & Effectiveness, [\%] & $\mathrm{i}$ & Input \\
\hline$\eta$ & Efficiency, [\%] & $\begin{array}{l}\min \\
\mathrm{NET}\end{array}$ & $\begin{array}{l}\text { Minimum } \\
\text { Net }\end{array}$ \\
\hline Symbols & & $\mathrm{n}$ & Normalized \\
\hline$A$ & Area, $\left[\mathrm{m}^{2}\right]$ & o & Out \\
\hline$c_{p}$ & Specific heat capacity, $[\mathrm{kJ} / \mathrm{kgK}]$ & $\mathrm{p}$ & Polytropic \\
\hline$h$ & Specific enthalpy, $[\mathrm{kJ} / \mathrm{kg}]$ & pp & Pinch point \\
\hline$\dot{m}$ & Mass flow rate, $[\mathrm{kg} / \mathrm{s}]$ & pump & Pump \\
\hline$n$ & Number of discretization points, [-] & ref & Reference \\
\hline$P$ & Pressure, [bar] & s & Isentropic \\
\hline$\dot{Q}$ & Heat transfer rate, $[\mathrm{kW}]$ & sat & Saturated \\
\hline$s$ & Entropy, $[\mathrm{kJ} / \mathrm{kgK}]$ & $\mathrm{sc}$ & Subcritical \\
\hline$T$ & Temperature, $\left[{ }^{\circ} \mathrm{C}\right]$ & $\mathrm{sh}$ & Superheated \\
\hline $\bar{U}$ & Average overall heat transfer coefficient, $\left[\mathrm{kW} / \mathrm{m}^{2} \mathrm{~K}\right]$ & tc & Transcritical \\
\hline$\dot{V}$ & Volume flow rate, $\left[\mathrm{m}^{3} / \mathrm{s}\right]$ & wf & Working fluid \\
\hline$\dot{W}$ & Mechanical power, $[\mathrm{kW}]$ & & \\
\hline$X$ & Mole fraction, [-] & & \\
\hline$x$ & Vapour quality, [-] & & \\
\hline
\end{tabular}

several advantages when considering utilization of low temperature heat [1]. This makes the ORC suited for environmentally-friendly power conversion from geothermal heat sources, concentrated solar energy, waste heat streams and as bottoming cycles for power plants.

An important part of the optimization and design of an ORC is the working fluid selection, since the properties of the working fluid affect both cycle performance and component design. The volume flow ratio, enthalpy drop and Mach number are some important parameters when considering expander design, while thermal conductivity and viscosity are key variables in heat exchanger design. Hazard levels, ozone depletion potential (ODP), global warming potential (GWP) and thermal stability must also be considered. When choosing a working fluid for an ORC, it is therefore necessary to consider many different parameters, in order to reach a feasible design. For example, it is possible that a thermodynamically beneficial working fluid requires infeasibly large heat exchanger areas or an overly expensive expander (e.g. a multi-stage axial turbine). The review on fluid selection studies recently provided by Bao and Zhao [2], gives an overview of the abundant literature which is available on fluid selection for pure fluids. Binary working fluids have been studied far less, despite the available literature suggesting possible performance benefits when zeotropic mixtures 
are used in ORCs.

The non-isothermal phase change of zeotropic mixtures, can be utilized to optimize the heat transfer processes in the evaporator and the condenser thus increasing the efficiency of the ORC [3]. Heberle et al. [4] optimized subcritical ORCs using the mixtures: isobutane/isopentane and R227ea/R245fa, as working fluids. The analysis showed that the second law efficiency of the best isobutane/isopentane mixture was $8 \%$ higher than that of pure isobutane. The best R227ea/R245fa mixture showed $0.8 \%$ higher second law efficiency than pure R227ea. For the isobutane/isopentane mixture, Heberle et al. [4] also showed that the condenser $U A$-value peaked with the second law efficiency, while the $U A$-values for the preheater and the evaporator remained close to constant over a range of mixture compositions.

Trapp and Colonna [5] maximized the net power output of an ORC for low grade waste heat recovery from a pre-combustion $\mathrm{CO}_{2}$ capture process as part of an integrated gasification combined cycle power plant. The waste heat stream was a $140^{\circ} \mathrm{C}$ syngas/water mixture which partly condensed as heat was transferred from the waste heat stream to the ORC. For this unconventional heat source they showed that it was thermodynamically beneficial to have a supercritical boiler pressure and/or a binary zeotropic working fluid in the ORC. The results of an exergy analysis indicated that the exergetic efficiency of the condenser increased by $31 \%$ when a binary mixture was used instead of a pure fluid, and that the exergetic efficiency of the primary heat exchanger (boiler) was increased by $4-6 \%$ when an ORC with a supercritical boiler pressure was used instead of a subcritical ORC. An estimation of the required condenser heat transfer area indicated that a larger condenser is needed for mixtures than for pure working fluids.

Chys et al. [6] optimized a large number of working fluids (pure fluids, binary mixtures and three-component mixtures) in ORCs. For their low temperature heat source they optimized eight different binary mixtures of hydrocarbons and refrigerants to reach maximum thermal efficiency. For cyclohexane the thermal efficiency increased from $10.85 \%$ to $11.57 \%$ when isopentane was combined with cyclohexane to form a binary zeotropic working fluid, and a further increase to $11.74 \%$ was obtained when isohexane was added to form a three-component working fluid mixture.

Papadopoulos et al. [7] recently presented a fluid selection method where the Computer Aided Molecular Design approach was used to find optimal molecular structures for fluids used in binary working fluid mixtures. The method was applied to maximize the exergetic efficiency of an ORC utilizing a heat stream with an inlet temperature at $95^{\circ} \mathrm{C}$ and yielded 10 
potentially optimal fluid mixtures containing neopentane and/or fluorinated hydrocarbons.

A fluid selection and optimization study of ORCs, considering a large group of binary mixtures as possible working fluids, combined with an evaluation of parameters which affect the design of components, for a non-condensing (temperature independent $c_{p}$ ) heat source, has not yet been published in the scientific literature. Previous studies on binary mixtures in ORCs concerned optimization and preliminary component design for specific fluid mixtures, while other studies have considered many different binary mixtures with a primary focus on efficiency maximization.

This paper provides an ORC optimization analysis where both pure fluids and mixtures are considered as possible working fluids. Two liquid water streams with inlet temperatures at $120^{\circ} \mathrm{C}$ and $90^{\circ} \mathrm{C}$ representing geothermal heat sources or industrial waste heat streams are chosen as the basis of the analysis. These low temperatures are chosen, since mixtures have shown beneficial performance compared to pure fluids when the hot fluid inlet temperature is low [3-7]. A systematic methodology using a genetic algorithm optimizer is developed to find promising pure fluids and mixtures for the maximization of the net ORC power output. Both subcritical-saturated, subcritical-superheated and transcritical ORCs are considered as possible solutions. The best candidates are evaluated based on: thermodynamic performance, pressure levels, volume flow ratio over the expander, a turbine size parameter, $\bar{U} A$-values, fluid hazard levels and GWP, which are the critical parameters for the expander design, heat exchanger design, safety and the environment. Furthermore, the critical temperature and the temperature glide of condensation are evaluated in order to investigate if the working fluids yielding maximum net power have common characteristics.

The paper begins with a description of the used methodology in Section 2. Then the results are presented in Section 3. Section 4 provides a discussion of the results and a comparison with the existing literature. Finally conclusions are given in Section 5.

\section{Methodology}

The ORC is optimized in its simplest configuration. In this configuration it consists of four components: a pump, a boiler, an expander and a condenser. For subcritical cycles the boiler contains a preheater, an evaporator and a superheater (optional). A sketch of the simple cycle can be seen in Fig. 1 (a), while Fig. 1 (b) shows a subcritical and a transcritical ORC with a zeotropic working fluid in a Ts-diagram.

The assumptions used in the numerical simulations are listed in Table 1. Additional assumptions are the following: no pressure loss in piping or heat exchangers, no heat loss 

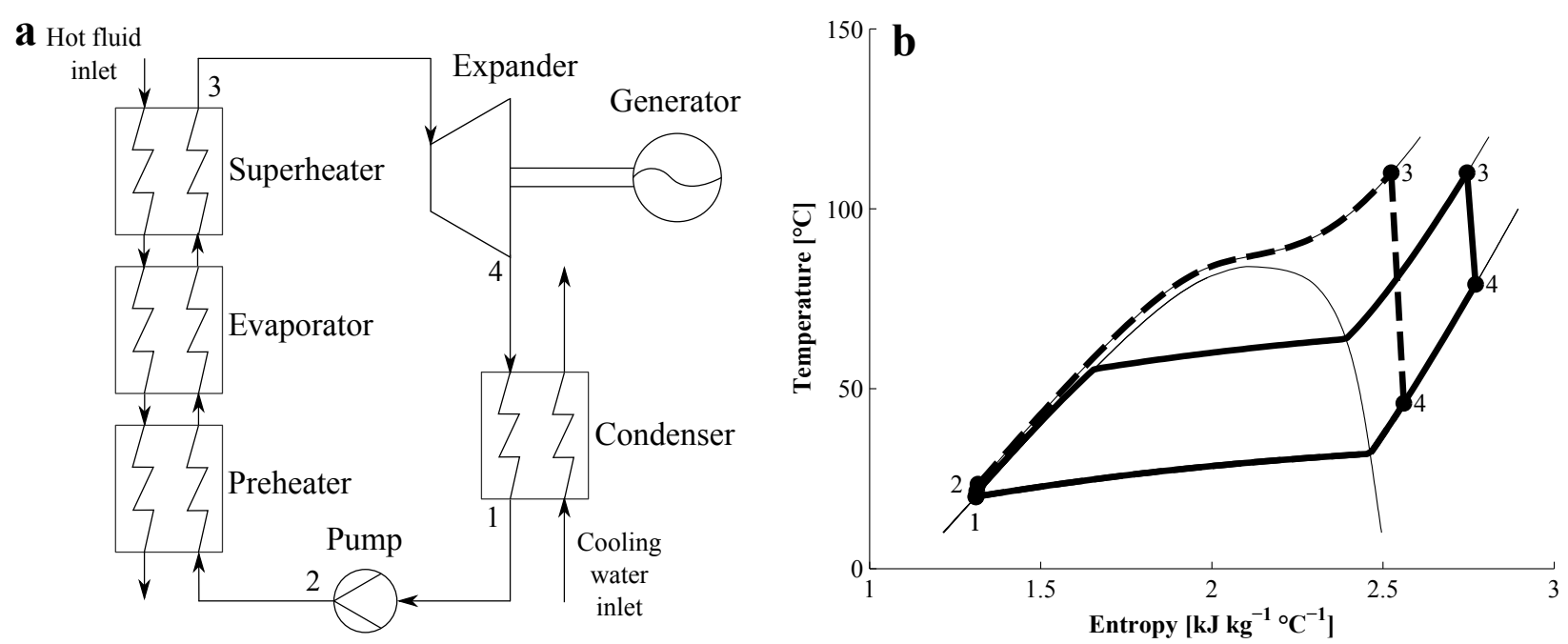

Figure 1: (a) a sketch of the ORC and (b) a subcritical (solid line) and a transcritical (dashed line) ORC process in a $T s$-diagram

from the system, steady state condition and homogeneous flow in terms of thermodynamic properties.

The net power, $\dot{W}_{N E T}$, given as the difference between the expander power and the pump power, is chosen as the objective function in the optimization

$$
\dot{W}_{N E T}=\dot{m}_{w f}\left[h_{3}-h_{4}-\left(h_{2}-h_{1}\right)\right]
$$

where $\dot{m}_{w f}$ is the mass flow of the working fluid and $h$ is the specific enthalpy.

The net power is chosen as the objective function, since the purpose of the ORC is to produce maximum net power using the available heat. The corresponding optimization variables can be expressed in an array as

$$
Y=\left[T_{3}, P_{3}, T_{h f, o}, \text { fluid } 1, \text { fluid } 2, X_{w f}\right]
$$

where $T$ is the temperature, $P$ is the pressure, and $X_{w f}$ is the composition of the working fluid (for mixtures).

Table 2 shows the optimization parameters, and the range in which they are allowed to vary. For the expander inlet temperature and the hot fluid outlet temperature, the upper limit is dependent on the hot fluid inlet temperature.

The parameters listed in Tables 1 and 2 are used to determine all state points and mass 
Table 1: Modeling conditions

\begin{tabular}{llr}
\hline Parameter description & Symbol & Value \\
\hline Hot fluid (water) & & \\
Hot fluid inlet temperature & $T_{h f, i}$ & $120^{\circ} \mathrm{C} \& 90^{\circ} \mathrm{C}$ \\
Hot fluid mass flow & $\dot{m}_{h f}$ & $50 \mathrm{~kg} / \mathrm{s}$ \\
Hot fluid pressure & $P_{h f}$ & $4 \mathrm{bar}$ \\
Condenser & & \\
Cooling water inlet temperature & $T_{\text {cool, }}$ & $15^{\circ} \mathrm{C}$ \\
Cooling water temperature rise & $\Delta T_{\text {cool }}$ & $5^{\circ} \mathrm{C}$ \\
Min. temperature difference & $\Delta T_{\text {cond }}$ & $5^{\circ} \mathrm{C}$ \\
Outlet vapour quality & $x_{1}$ & 0 \\
Cooling water pressure & $P_{\text {cool }}$ & $4 \mathrm{bar}$ \\
Condenser steps & $n_{\text {cond }}$ & 10 \\
Pump & & \\
Isentropic efficiency & $\eta_{s, \text { pump }}$ & 0.8 \\
Boiler & & \\
Min. temperature difference & $\Delta T_{\text {boil }}$ & 10 \\
Boiler steps & $n_{\text {boil }}$ & \\
Expander & & 10 \\
Polytropic efficiency & $\eta_{p, \text { exp }}$ & 50 \\
Min. vapour quality & $x_{\text {exp } \text { min }}$ & \\
Expansion steps & $n_{\text {exp }}$ & \\
\hline & & \\
\hline
\end{tabular}

Table 2: Optimization parameters and range of parameter variation

\begin{tabular}{llr}
\hline Parameter description & Symbol & Range \\
\hline Expander inlet temperature & $T_{3}$ & $20^{\circ} \mathrm{C}-110 / 80^{\circ} \mathrm{C}$ \\
Expander inlet pressure & $P_{3}$ & $0.1 \mathrm{bar}-100 \mathrm{bar}$ \\
Hot fluid outlet temperature & $T_{h f, o}$ & $20^{\circ} \mathrm{C}-110 / 80^{\circ} \mathrm{C}$ \\
First working fluid & - & - \\
Second working fluid & - & - \\
Mole composition & $X_{w f}$ & $0-1$ \\
\hline
\end{tabular}

flows in the ORC. The condenser pinch point is used to determine the condensation pressure, and the boiler pinch point is used to check if the minimum limit on the boiler pinch point is violated for the given hot fluid outlet temperature $T_{h f, o}$ and boiler pressure $P_{3}$. The thermal energy input and the net power output of the ORC vary depending on the outcome of the optimizations. For the hot fluid characteristics chosen in this paper, the thermal energy input to the cycle varies in the ranges 12.0-17.4 MW and 7.4-10.9 MW, while the net power output varies in the ranges 1.0-1.5 MW and 0.4-0.6 MW for the $120^{\circ} \mathrm{C}$ and $90^{\circ} \mathrm{C}$ hot fluid inlet temperature cases, respectively.

The thermodynamic simulation models were created using Matlab language, and the database provided by Lemmon et al. [8] was used to obtain thermodynamic property data. 
All pure fluids and predefined mixtures (e.g. R507A and R404A), with ODP =0, within the database are included as potential fluid candidates. The group of predefined mixtures consists of mixtures including up to five fluids, and these mixtures are treated as pure fluids in the optimizations. The property database also provides the possibility of combining pure fluids to form mixtures of arbitrary composition. In this study we only consider the possibility of combining pure fluids in binary mixtures. In order to ensure reliable property data for these mixtures, we only consider mixtures, for which accurate and validated property data is available. Accurate property data models for mixtures (relevant as ORC working fluids) are provided by: Lemmon and Jacobsen [9] (R32, R125, R134a, R143a, R152a) and Kunz and Wagner [10] (natural gas components, primarily hydrocarbons). For the pure fluids reported in this paper the highest estimated uncertainties are the following: $1 \%$ in density, $2 \%$ in speed of sound and $5 \%$ in heat capacities, within the temperature and pressure ranges encountered in the optimizations. For the refrigerant mixtures in the model of Lemmon and Jacobsen [9] the estimated uncertainties are: $0.1 \%$ in density, $0.5 \%$ in speed of sound and $0.5 \%$ in heat capacities. For the mixtures in the model of Kunz and Wagner [10] the estimated uncertainties are: $0.5 \%$ in density, $0.1 \%$ in speed of sound and $2 \%$ in heat capacities. The uncertainties are higher close to the critical point.

\subsection{Solution assessment}

The requirements of the heat exchangers are estimated based on the $\bar{U} A$-value, which is the product of the average overall heat transfer coefficient $(\bar{U})$ and the heat transfer area $(A)$. The overall heat transfer coefficient depends on fluid properties and flow characteristics, and the area is determined by the heat exchanger design and is directly related to heat exchanger cost. The $\bar{U} A$-value is thereby not a direct measure of the heat exchanger cost, since $\bar{U}$ may vary for the various solutions, but it gives an indication of the requirements and costs related to the design of the heat exchangers.

For the power ranges of the ORCs considered in this paper, it is reasonable to use an axial turbine as the expander. The usually low enthalpy drop of organic fluids makes it possible to design efficient and low cost single stage turbines for ORCs. Macchi and Perdichizzi [11] related the volume flow ratio over the turbine $\dot{V}_{4} / \dot{V}_{3}$ and the turbine size parameter $\sqrt{\dot{V}_{4}} /\left(\Delta h_{s}\right)^{0.25}$ to the isentropic efficiency of a single stage axial turbine. It is possible that an ORC solution yielding a large net power output, is not able to reach the desired turbine efficiency with a simple single stage turbine design. In this case it is necessary to use one or more additional stages (increasing the cost of the turbine) to attain the desired turbine efficiency. Based on the work of Macchi and Perdichizzi [11], Astolfi et al. [12] used two 
criteria to evaluate whether one or more turbine stages were needed for their axial ORC turbines. In order to avoid high Mach numbers and large blade height variations, leading to increased losses, they set a limit on the volume flow ratio for a single stage to 4 , and in order to avoid high mechanical stresses they limited the stage enthalpy drop to $65 \mathrm{~kJ} / \mathrm{kg}$. Furthermore, they used the size parameter to estimate the cost of the turbines. In this paper we use the above criteria to compare the turbine designs of the ORC solutions.

Hazard levels and GWP of the working fluid are very important parameters to consider when assessing a given ORC solution, since these parameters influence the safety of the system and the environment. In order to evaluate the hazards of the system, the HMIS (Hazardous Materials Identification System) rating system [13] is used. Here the hazards are divided into three categories: health hazards (h), flammability (f) and physical hazards (p). For mixtures the maximum hazards for each of the three categories are shown. The GWP is given for a 100 year time horizon evaluated with $\mathrm{CO}_{2}$ as the reference [14, 15], and for mixtures it is estimated as a weighted average of the GWP of the pure fluids based on mass fractions.

In order to make the results independent of the hot fluid mass flow and heat capacity $\left(c_{p}\right)$, the net power and the $\bar{U} A$-value are normalized with $\dot{m}_{h f} c_{p, h f} T_{h f, i}$ and $\dot{m}_{h f} c_{p, h f}$, respectively. All results, except the turbine size parameter, are therefore also valid for other hot fluids and hot fluid mass flows, given that the assumed parameters in Table 1 (except $\dot{m}_{h f}$ and $P_{h f}$ ) are used, the $c_{p}$ of the hot fluid is approximately independent of temperature, no limitation on the hot fluid outlet temperature applies and that the power output of the ORC is in a range which makes it reasonable to use an axial turbine expander. This is true, since a variation in the mass flow and/or $c_{p}$ of the hot fluid, simply scales the working fluid mass flow, the cooling water mass flow and the net power output. The mass flow and $c_{p}$ of the hot fluid, therefore, do not impact the outcome of the optimizations, when the above conditions are satisfied.

The normalized net power $\dot{W}_{n}$ is defined as

$$
\dot{W}_{n}=\frac{\dot{W}_{N E T}}{\dot{m}_{h f} c_{p, h f} T_{h f, i}}
$$

With $T_{h f, i}$ given in ${ }^{\circ} \mathrm{C}$, the quantity used for normalization $\dot{m}_{h f} c_{p, h f} T_{h f, i}$ is $25.46 \mathrm{MW}$ for the $120^{\circ} \mathrm{C}$ hot fluid inlet temperature case and $18.92 \mathrm{MW}$ for the $90^{\circ} \mathrm{C}$ hot fluid inlet temperature case.

The thermodynamic performance of an ORC utilizing sensible heat is dependent on the heat recovery effectiveness $\epsilon$ and the thermal efficiency $\eta_{I}$. These performance parameters 
are therefore included in the solution assessment. The heat recovery effectiveness is defined as

$$
\epsilon=\frac{h_{h f, i}-h_{h f, o}}{h_{h f, i}-h_{h f, r e f}}
$$

where $h_{h f, r e f}$ is the specific enthalpy of water at $T=20^{\circ} \mathrm{C}$ (equal to the cooling water outlet temperature) and $P=P_{h f}$.

The thermal efficiency is defined as

$$
\eta_{I}=\frac{\dot{W}_{N E T}}{\dot{m}_{h f}\left(h_{h f, i}-h_{h f, o}\right)}
$$

\subsection{Optimization procedure}

The optimizations of this paper are carried out using the genetic algorithm available through the ga-function in Matlab [16]. The input parameters given to the genetic algorithm are shown in Table 3.

Table 3: Specified input parameters to the genetic algorithm

\begin{tabular}{lr}
\hline Parameter & Value \\
\hline Population size & 100 \\
Total number of generations & $500 / 200$ \\
Maximum number of stalled generations & 500 \\
Minimum tolerance & 0 \\
Elite count & 2 \\
Crossover fraction & 0.7 \\
\hline
\end{tabular}

For each hot fluid inlet temperature the optimization is divided in an optimization considering only pure fluids (including predefined mixtures) and an optimization considering mixtures for which the composition can be optimized. For the pure fluids the optimization is carried out using 500 generations. For mixtures an initial optimization (500 generations) is followed by an additional optimization (200 generations), where the two working fluids in the mixture are kept fixed, such that the turbine inlet state, the hot fluid outlet temperature and the mixture composition are the only optimized parameters. This approach is chosen, since the additional optimization parameters in the mixture optimizations (second working fluid and the mixture composition) make it difficult to obtain high accuracies on the optimizations. When a binary mixture reaches a lower net power output than any of the 
pure fluids in the mixture, then the mixture is discarded. The same is the case for multicomponent predefined mixtures when better performance can be achieved by excluding one or more fluids from the mixture. In order to ensure that all relevant fluids are considered in the optimizations, the optimization procedure is carried out to find more fluids than those presented in the paper, such that each fluid candidate has many changes of "being discovered" by the genetic algorithm.

The discretization of the heat exchangers is quite coarse and may lead to violation of pinch points in the boiler. When the boiler pressure is well below the critical pressure, the pinch point is typically located at the saturated liquid point. This point is therefore included as an additional point in the boiler discretization, which ensures high accuracy of the discretization. When the boiler pressure is subcritical and close to the critical pressure or supercritical, it is difficult to predict the location of the pinch point, and $n_{\text {boil }}=10$ may be insufficient to ensure high accuracy. A calculation with $n_{\text {boil }}=100$ is therefore carried out for each of the found solutions, in order to evaluate the difference between the pinch points of the solution with $n_{\text {boil }}=10$ and the solution with $n_{\text {boil }}=100$. If the pinch points deviate more than $0.05^{\circ} \mathrm{C}$, then the solution is run through an additional optimization in the genetic algorithm (200 generations), where the turbine inlet state, the hot fluid outlet temperature and the mixture composition (only for mixtures) are optimized again with $n_{\text {boil }}=30$. Using $n_{\text {cond }}=10$ for the condenser was found to be adequate for all solutions.

In order to check that the thermodynamic models provide reasonable results, and that the genetic algorithm reaches satisfactory convergence, the models are validated by comparing the results with similar results from the literature. For pure fluids the model is validated with the exergetic plant efficiencies found by Walraven et al. [17] for a simple ORC configuration (excluding R227ea and $\mathrm{C}_{4} \mathrm{~F}_{10}$ due to expansion through the two phase region) and the thermal efficiencies found by Larsen et al. [18] for the simple ORC (with a maximum pressure limit of 20 bar) and the recuperated ORC. The largest relative deviation encountered is $3.27 \%$. For mixtures the model is validated with the second law efficiencies found by Heberle et al. [4] and the cycle efficiencies found by Chys et al. [6] (mixtures: R245fa/R365mfc, $\mathrm{R} 245 \mathrm{fa} /$ isopentane, $\mathrm{R} 245 \mathrm{fa} /$ pentane and isopentane/cyclohexane). The maximum relative deviation for this validation is $1.81 \%$. The use of different versions of the property database by Lemmon et al. [8], small differences in the modeling conditions (e.g. heat exchanger discretization) and the possible event that the genetic algorithm does not achieve complete convergence are deemed to cause the discrepancies in the validation. 


\section{Results}

Table 4: Results for the $120^{\circ} \mathrm{C}$ hot fluid inlet temperature case

\begin{tabular}{|c|c|c|c|c|c|c|c|c|c|c|c|c|c|c|}
\hline Fluids & $\begin{array}{r}\dot{V}_{n} \cdot 10^{2} \\
{[-]}\end{array}$ & $\begin{array}{c}\eta_{I} \\
{[\%]}\end{array}$ & $\begin{array}{r}\epsilon \\
{[\%]}\end{array}$ & $\begin{array}{l}X_{w f} \\
{[\%]}\end{array}$ & $\begin{array}{l}P_{b o i l} \\
{[\text { bar] }}\end{array}$ & $\begin{array}{l}P_{\text {cond }} \\
\text { [bar] }\end{array}$ & $\begin{array}{r}T_{3} \\
{\left[{ }^{\circ} \mathrm{C}\right]}\end{array}$ & $\begin{array}{l}T_{h f, o} \\
{\left[{ }^{\circ} \mathrm{C}\right]}\end{array}$ & $\begin{array}{l}\Delta T_{g} \\
{\left[{ }^{\circ} \mathrm{C}\right]}\end{array}$ & $\begin{array}{l}\dot{V}_{4} \\
\dot{V}_{3} \\
{[-]}\end{array}$ & $\begin{array}{l}\frac{\sqrt{\dot{V}_{4}}}{\Delta h_{s}^{1 / 4}} \\
{[\mathrm{~cm}]}\end{array}$ & $\begin{array}{c}\frac{\bar{U} A_{t o t}}{\left(\dot{m} c_{p}\right)_{h s}} \\
{[-]}\end{array}$ & $\begin{array}{l}\text { Hazard } \\
{[\mathrm{f} / \mathrm{h} / \mathrm{p}]}\end{array}$ & $\begin{array}{r}\text { GWP } \\
{[-]}\end{array}$ \\
\hline $\mathrm{R} 218^{t c}$ & 5.76 & 8.8 & 79.4 & & 46.5 & 8.5 & 102.9 & 40.7 & & 9.18 & 13.32 & 16.5 & $1 / 2 / 1$ & 8830 \\
\hline $\mathrm{R} 422 \mathrm{~A}^{t c}$ & 5.71 & 9.5 & 72.9 & & 57.4 & 12.3 & 102.2 & 47.2 & 1.4 & 6.27 & 10.04 & 15.5 & $4 / 1 / 0$ & 3143 \\
\hline $\mathrm{R} 125^{t c}$ & 5.66 & 9.2 & 74.2 & & 57.7 & 13.7 & 100.8 & 45.9 & & 5.45 & 9.95 & 15.0 & $/ 1 / 0$ & 3500 \\
\hline eth./prop. ${ }^{t c}$ & 5.53 & 8.9 & 75.3 & 87.5 & 89.7 & 32.5 & 110.0 & 44.8 & 6.3 & 2.67 & 5.83 & 17.2 & $4 / 1 / 0$ & 3 \\
\hline $\mathrm{R} 41^{t c}$ & 5.53 & 9.3 & 71.9 & & 97.0 & 37.6 & 110.0 & 48.2 & & 2.21 & 5.38 & 14.4 & $3 / 2 / 2$ & 92 \\
\hline $\mathrm{R} 143 \mathrm{a}^{t c}$ & 5.46 & 9.5 & 69.4 & & 49.3 & 12.6 & 97.2 & 50.7 & & 4.86 & 9.37 & 13.4 & $1 / 1 / 0$ & 4470 \\
\hline & 5.38 & 8.7 & 75.2 & 95.9 & & & 110.0 & 44.9 & 6.9 & 2.52 & 5.74 & 17.1 & & 3 \\
\hline eth./b & 5.37 & 8.7 & 75.1 & 96.4 & 94.9 & 35.7 & 110.0 & 45.0 & 8.0 & 2.53 & 5.71 & 17.0 & & 3 \\
\hline eth./ipent. ${ }^{t c}$ & 5.30 & 8.5 & 75.5 & 97.4 & 93.2 & 36.1 & 110.0 & 44.6 & 10.3 & 2.46 & 5.74 & 16.6 & $4 / 1 / 0$ & 3 \\
\hline eth./pent. ${ }^{t c}$ & 5.26 & 8.4 & 76.3 & 97.9 & 89.7 & 36.4 & 110.0 & 43.8 & 13.0 & 2.36 & 5.78 & 16.3 & $4 / 2 / 0$ & 3 \\
\hline eth./hex. ${ }^{t c}$ & 5.22 & 8.4 & 75.2 & 98.9 & 93.9 & 37.4 & 110.0 & 44.9 & 15.8 & 2.38 & 5.71 & 16.4 & $4 / 2 / 0$ & 3 \\
\hline $\mathrm{SF} 6^{t c}$ & 5.21 & 8.3 & 76.1 & & 78.3 & 22.8 & 106.4 & 44.0 & & 3.90 & 8.94 & 15.2 & $/ 0$ & 22800 \\
\hline eth./hept. ${ }^{t c}$ & 5.19 & 8.5 & 74.2 & 99.3 & 97.1 & 38.0 & 110.0 & 45.9 & 21.8 & 2.41 & 5.65 & 16.3 & $4 / 1 / 0$ & 3 \\
\hline ethane $^{t c}$ & 4.90 & 8.2 & 72.1 & & 96.2 & 40.2 & 110.0 & 48.0 & & 2.25 & 5.64 & 14.1 & $4 / 1 / 0$ & 3 \\
\hline $\mathrm{R} 32_{s h}^{s c}$ & 4.87 & 10.3 & 57.1 & & 53.1 & 16.8 & 110.0 & 63.0 & & 2.84 & 6.36 & 10.1 & $4 / 1 / 1$ & 675 \\
\hline $\mathrm{CO} 2 /$ ibut $^{t c}$ & & 7.2 & 81.4 & 88.6 & 100.0 & & 110.0 & & & 1.84 & 5.79 & 14.8 & & 1 \\
\hline $\mathrm{CO} 2 /$ but & 4.86 & 7.1 & 81.8 & 90.9 & 100.0 & 50.5 & 110.0 & 38.3 & 15.8 & 1.79 & 5.80 & 15.0 & & 1 \\
\hline $\mathrm{R} 1234 \mathrm{yf}_{s c}^{s c}$ & 4.83 & 9.3 & 63.2 & & 24.2 & 6.8 & 79.0 & 57.0 & & 4.51 & 12.21 & 11.1 & $0 / 2 / 0$ & 4 \\
\hline & 4.78 & 9.4 & 61.5 & & 18.7 & 4.5 & 80.2 & 58.7 & & 5.41 & 14.57 & 10.6 & $-/-/-$ & 3220 \\
\hline $\mathrm{C} 4 \mathrm{~F} 10_{\text {sat }}^{\text {sat }}$ & 4.75 & 8.6 & 67.0 & & 10.6 & 2.6 & 75.9 & 53.1 & & 5.00 & 19.96 & 11.3 & $0 / 1 / 0$ & 8860 \\
\hline prop./ibut.sct & 4.75 & 9.5 & 60.8 & 80.2 & & & & & 5.2 & 3.52 & 9.56 & 13.2 & & 3 \\
\hline $\mathrm{CO} 2 /$ prop. & 4.74 & 9.1 & 63.2 & 2.1 & 29.7 & 9.7 & 78.7 & 56.9 & 5.0 & 3.45 & 8.67 & 12.0 & $4 / 1 / 0$ & 3 \\
\hline prop./but. $\begin{array}{c}s h \\
s h\end{array}$ & 4.73 & 9.4 & 61.1 & 89.2 & 24.1 & 7.7 & 76.4 & 59.0 & 6.0 & 3.45 & 9.32 & 13.0 & $4 / 1 / 0$ & 3 \\
\hline prop./ipent. ${ }_{s h}^{s c}$ & 4.69 & 9.1 & 62.3 & 94.6 & 24.2 & 8.1 & 76.9 & 57.9 & 9.2 & 3.27 & 9.30 & 12.6 & $4 / 1 / 0$ & 3 \\
\hline prop./pent. $\begin{array}{c}s c \\
s h \\
s h\end{array}$ & 4.69 & 9.3 & 61.4 & 96.7 & 25.3 & 8.4 & 78.0 & 58.8 & 7.9 & 3.33 & 9.09 & 12.5 & $4 / 2 / 0$ & 3 \\
\hline prop./hex. ${ }_{s h}^{s c}$ & 4.63 & 9.3 & 60.2 & 98.1 & 25.6 & 8.5 & 83.2 & 59.9 & 14.2 & 3.26 & 8.86 & 11.8 & & 3 \\
\hline ibut./ipent. sat $_{\text {sat }}$ & 4.56 & 9.2 & 60.1 & 82.0 & 8.9 & 2.6 & 73.8 & 60.0 & 7.7 & 3.54 & 14.64 & 12.0 & $4 / 1 / 0$ & 3 \\
\hline but./ipent. sc sat & 4.55 & 9.4 & 58.5 & 71.9 & 6.4 & 1.7 & 72.1 & 61.6 & 5.4 & 3.77 & 16.97 & 12.4 & $4 / 1 / 0$ & 3 \\
\hline & 4.53 & 9.2 & 59.4 & 81.4 & 6.4 & 1.8 & 72.3 & 60.8 & 7.0 & 3.64 & 16.76 & 12.1 & & 3 \\
\hline propylene ${ }_{s h}^{s c}$ & 4.49 & 9.5 & 57.2 & & 34.8 & 11.5 & 86.1 & 63.0 & & 3.28 & 7.69 & 9.8 & $4 / 1 / 1$ & 3 \\
\hline
\end{tabular}

Tables 4 and 5 show the results of the $\mathrm{ORC}$ optimization for the $120^{\circ} \mathrm{C}$ and $90^{\circ} \mathrm{C}$ hot fluid inlet temperature cases. The 30 fluids giving the highest net power are sorted with respect to normalized net power in descending order. Subcritical and transcritical solutions are indicated with superscripts $s c$ and $t c$, respectively, and for the subcritical solutions the subscript indicates either a superheated $(s h)$ or saturated (sat) condition at the turbine inlet. We define a solution as superheated when $T_{3}>T_{\text {sat }}+1$, and as saturated when $T_{\text {sat }} \leq T_{3} \leq T_{\text {sat }}+1$ (for mixtures the dew point temperature is used instead of the saturation temperature $T_{\text {sat }}$ ). The mole composition of the more volatile component $X_{w f}$ and the temperature glide of condensation $\Delta T_{g}$ are only provided for mixtures. 
Table 5: Results for the $90^{\circ} \mathrm{C}$ hot fluid inlet temperature case

\begin{tabular}{|c|c|c|c|c|c|c|c|c|c|c|c|c|c|c|}
\hline Fluids & $\begin{array}{r}\dot{V}_{n} \cdot 10^{2} \\
{[-]}\end{array}$ & $\begin{array}{c}\eta_{I} \\
{[\%]}\end{array}$ & $\begin{array}{r}\epsilon \\
{[\%]}\end{array}$ & $\begin{array}{l}X_{w f} \\
{[\%]}\end{array}$ & $\begin{array}{l}P_{b o i l} \\
{[\text { bar] }}\end{array}$ & $\begin{array}{l}P_{\text {cond }} \\
\text { [bar] }\end{array}$ & $\begin{array}{r}T_{3} \\
{\left[{ }^{\circ} \mathrm{C}\right]}\end{array}$ & $\begin{array}{l}T_{h f, o} \\
{\left[{ }^{\circ} \mathrm{C}\right]}\end{array}$ & $\begin{array}{l}\Delta T_{g} \\
{\left[{ }^{\circ} \mathrm{C}\right]}\end{array}$ & $\begin{array}{l}\dot{V}_{4} \\
\dot{V}_{3} \\
{[-]}\end{array}$ & $\begin{array}{l}\frac{\sqrt{\dot{V}_{4}}}{\Delta h_{s}^{1 / 4}} \\
{[\mathrm{~cm}]}\end{array}$ & $\begin{array}{c}\frac{\bar{U} A_{t o t}}{\left(\dot{m} c_{p}\right)_{h s}} \\
{[-]}\end{array}$ & $\begin{array}{l}\text { Hazard } \\
{[\mathrm{f} / \mathrm{h} / \mathrm{p}]}\end{array}$ & $\begin{array}{r}\text { GWP } \\
{[-]}\end{array}$ \\
\hline eth./prop. ${ }^{t c}$ & 3.21 & 6.1 & 68.5 & 86.9 & 60.3 & 32.3 & 80.0 & 42.1 & 6.5 & 1.87 & 5.40 & 11.1 & $4 / 1 / 0$ & 3 \\
\hline 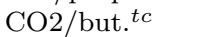 & 15 & .6 & 2.4 & 1.8 & & & 0.0 & & & .60 & 4.92 & 11.9 & & 1 \\
\hline h. $/$ ibut. $^{t c}$ & 13 & 5.7 & 70.7 & 95.6 & 62.8 & & 9.8 & & & .77 & 5.46 & 11.3 & & 3 \\
\hline eth./but. ${ }^{t c}$ & 3.12 & 5.7 & 70.3 & 95.7 & 63.1 & & 79.9 & 40.8 & 9.5 & 1.78 & 5.41 & 11.0 & $4 / 1 / 0$ & 3 \\
\hline eth./ipent. ${ }^{t c}$ & 3.10 & 5.7 & 70.6 & 97.7 & 64.5 & 36.5 & 80.0 & 40.6 & 8.9 & 1.75 & 5.43 & 11.2 & $4 / 1 / 0$ & 3 \\
\hline eth./pent. ${ }^{t c}$ & 3.09 & 5.7 & 70.5 & 98.2 & 65.1 & 36.9 & 80.0 & 40.7 & 10.9 & 1.74 & 5.40 & 11.1 & $4 / 2 / 0$ & 3 \\
\hline $\mathrm{R} 41^{t c}$ & 3.07 & 6.5 & 60.6 & & 74.2 & 37.9 & 79.9 & 47.6 & & 1.76 & 4.64 & 8.8 & & 92 \\
\hline $\mathrm{SF} 6^{t c}$ & 3.06 & 6.0 & 65.5 & & 51.2 & 23.1 & 75.5 & 44.2 & & 2.61 & 8.17 & 9.5 & $/ 1 / 0$ & 22800 \\
\hline $\mathrm{CO} 2 /$ prop $^{t c}$ & 05 & 5.3 & 73.9 & 82.1 & 85.1 & & 80.0 & 38.3 & 6.1 & 1.58 & 5.26 & 11.9 & $4 / 1 / 0$ & 1 \\
\hline ethane $^{t c}$ & 2.89 & 5.8 & 64.8 & & 74.2 & 40.6 & 80.0 & 44.7 & & 1.78 & 5.18 & 9.6 & $4 / 1 / 0$ & 3 \\
\hline $\mathrm{R} 218_{\text {sat }}^{s c}$ & 2.78 & 6.2 & 57.8 & & 20.3 & 8.6 & 60.1 & 49.6 & & 3.24 & 11.50 & 7.7 & $1 / 2 / 1$ & 8830 \\
\hline R419 & 2.77 & 6.4 & 55.8 & & 21.7 & 9 & 57. & 51.0 & 5.4 & 2.47 & 9.06 & 9.0 & $1 / 2$ & 2967 \\
\hline $\mathrm{R} 32 / 134 \mathrm{a}_{s h}^{s c}$ & 2.75 & 6.8 & 52.6 & 64.7 & 24.3 & 11.4 & 80.0 & 53.2 & 5.3 & 2.09 & 7.16 & 8.3 & $4 / 1 / 1$ & 1066 \\
\hline $\mathrm{CO} 2^{t c}$ & 2.74 & 5.1 & 69.5 & & 100.0 & 62.2 & 80.0 & 41.3 & & 1.46 & 4.91 & 9.5 & $1 / 0$ & 1 \\
\hline $\mathrm{R} 125 / \mathrm{R} 152 \mathrm{a}_{s h}^{s c}$ & 2.72 & 6.6 & 53.6 & 56.3 & 20.6 & 9.3 & 65.8 & 52.5 & 4.8 & 2.33 & 8.63 & 8.7 & $4 / 1 / 1$ & 2489 \\
\hline $\mathrm{R} 143 \mathrm{a} / \mathrm{R} 152 \mathrm{a}_{s h}^{s c}$ & $\begin{array}{ll}c \\
h\end{array}$ & 6.5 & 53.0 & 34.9 & 16.1 & 7.5 & 77.7 & 53.0 & 4.4 & 2.14 & 8.66 & 8.3 & $4 / 1 / 1$ & 1888 \\
\hline $\mathrm{R} 32 / \mathrm{R} 152 \mathrm{a}_{s h}^{s c}$ & 2.68 & 6.7 & 51.7 & 19.7 & 15.1 & 6.9 & 77.2 & 53.8 & 4.9 & 2.13 & 8.46 & 7.7 & $/ 1 / 1$ & 213 \\
\hline $\mathrm{R} 125 / \mathrm{R} 134 \mathrm{a}_{s h}^{s c}$ & 2.67 & 6.3 & 54.4 & 54.0 & 20.6 & 9.4 & 65.1 & 52.0 & 3.6 & 2.34 & 8.98 & 8.3 & $1 / 1 / 0$ & 2630 \\
\hline & 2.66 & 6.6 & 51.9 & 77.3 & 15.0 & 7.1 & 57.0 & 53.7 & 5.6 & 2.20 & 8.39 & 8.3 & $4 / 1 / 0$ & 3 \\
\hline but./ipent.sc $s a t$ & 2.65 & 6.6 & 51.7 & 67.0 & 4.0 & 1.6 & 55.7 & 53.9 & 5.9 & 2.43 & 15.26 & 8.1 & $4 / 1 / 0$ & 3 \\
\hline $\mathrm{R} 32 / \mathrm{R} 125_{s h}^{s c}$ & 2.65 & 6.6 & 52.3 & 3.5 & 33.1 & 13.9 & 65.9 & 53.5 & 0.1 & 2.87 & 7.99 & 6.9 & $4 / 1 / 1$ & 3456 \\
\hline ibut./ip & 2.64 & 6.7 & 51.0 & 81.5 & 6.1 & 2. & 58 & 54.3 & 7 . & 2.38 & 12.58 & 7.7 & $4 / 1 / 0$ & 3 \\
\hline prop./b & 2.64 & 6.6 & 51.8 & 86.0 & 15.6 & 7.4 & 62.3 & 53.8 & 7. & 2.17 & 8.09 & 7.9 & $4 / 1 / 0$ & 3 \\
\hline /pent. sat $_{\text {sat }}$ & 2.62 & 6.6 & 51.3 & 84.8 & 6. & 2. & 59. & & 9.8 & 2.36 & 12.49 & 7.5 & & 3 \\
\hline prop./ipent. ${ }_{s h}^{s c}$ & 2.61 & 6.5 & 52.0 & 93.3 & 16.4 & 7.9 & 61.3 & 53.6 & 11.2 & 2.15 & 7.97 & 7.7 & $4 / 1 / 0$ & 3 \\
\hline $\mathrm{R} 125 / \mathrm{R} 143 \mathrm{a}_{s h}^{s c}$ & 2.61 & 6.3 & 53.1 & 90.1 & 30.6 & 13.5 & 63.6 & 52.9 & 0.1 & 2.69 & 8.22 & 6.9 & $1 / 1 / 0$ & 3569 \\
\hline & 2.60 & 6.5 & 52.0 & 94.3 & 16. & 8.1 & 63. & 53.6 & 13.0 & 2.13 & 7.92 & 7.7 & $4 / 2 / 0$ & 3 \\
\hline hept./oct. & 2.60 & 6.6 & 50.7 & 39.9 & 0.1 & 0.0 & 56.0 & 54.6 & 6.3 & 4.08 & 89.03 & 7.2 & $3 / 2 / 0$ & 3 \\
\hline $\mathrm{R} 125_{s h}^{s c}$ & 2.59 & 5.7 & 58.4 & & 28.4 & 13.8 & 58.0 & 49.1 & & 2.41 & 8.94 & 7.6 & $1 / 1 / 0$ & 3500 \\
\hline $\mathrm{R} 143 \mathrm{a} / \mathrm{R} 134 \mathrm{a}_{s h}^{s c}$ & 2.59 & 6.5 & 51.9 & 57.7 & 19.4 & 9.1 & 76.1 & 53.7 & 2.8 & 2.20 & 8.46 & 7.4 & $1 / 1 / 0$ & 3038 \\
\hline
\end{tabular}

\subsection{High performance fluids}

For the $120^{\circ} \mathrm{C}$ hot fluid inlet temperature case, R218 is the best performing fluid when the net power of the ORC is considered. Compared to the other fluids in the top half of the table, R218 has low pressure and hazard levels, which are desirable properties. On the other hand R218 has a high GWP, high total $\bar{U} A$, a high turbine size parameter and high turbine volume flow ratio, indicating high investment costs and large environmental consequences if a leakage occurs.

R125 and R143a both reach a high net power output, but many of the mixtures containing one or both of these two fluids are discarded due to too low net power outputs. R422A (a mixture of R125/R134a/isobutane $85.1 \% / 11.5 \% / 3.4 \%$ by mass) on the other hand outperforms R125 when rated on net power output.

By comparing performance values for pure ethane with the ethane mixtures, one sees 
that the mixtures achieve higher net power outputs at lower boiler and condenser pressures than pure ethane (ethane/heptane is the only case where the boiler pressure is not reduced). The relative increase in the net power of the ethane/propane solution is $12.9 \%$ compared to the pure ethane solution. The results also indicate that the mixture solutions require larger heat exchangers, since the $\bar{U} A$-values are larger for the mixtures than for pure ethane. For the ethane mixtures the highest performance is reached, when the other fluid in the mixture has a boiling point close to the boiling point of ethane.

For the $90^{\circ} \mathrm{C}$ hot fluid inlet temperature case, the results also suggest that high pressure levels and $\bar{U} A$-values are required in order to obtain maximum net power. The best performing fluids are ethane mixtures with ethane as the dominating fluid. The optimal ethane mixture is again ethane/propane, with a net power increase of $11.1 \%$ compared to pure ethane. As for the $120^{\circ} \mathrm{C}$ hot fluid inlet temperature optimization, the mixtures achieve a pressure decrease, while the total cycle $\bar{U} A$-value increases, compared to pure ethane.

For the $90^{\circ} \mathrm{C}$ hot fluid inlet temperature case, the binary refrigerant mixtures do in many cases obtain a net power increase compared to the pure refrigerants. The best performing refrigerant mixture is the predefined mixture R419A (a mixture of R125/R134a/dimethylether $77 \% / 19 \% / 4 \%$ by mass). Comparing R125 to R125/R152a and R134a/R125, one sees that these refrigerant mixtures also achieve the net power increase at lower pressure levels and with higher total cycle $\bar{U} A$-values, as is the case for the ethane mixtures. For this hot fluid inlet temperature, R218 shows benefits such as high net power output, low pressure levels, low total $\bar{U} A$-value and low hazard level.

For both hot fluid inlet temperatures the highest net power can only be reached if high pressures and high $\bar{U} A$-values are accepted. The high pressures in the boiler and the condenser require that pressure resistant equipment is used in order to prevent leakages or equipment failure at high pressure operation. Furthermore, it is desirable to have above atmospheric condensation pressure, such that ambient air is prevented from entering the condenser. All fluids, except heptane/octane, condense at pressures above the atmospheric pressure.

\subsection{Heat recovery effectiveness and thermal efficiency}

In general the transcritical cycles achieve the highest power output compared to the subcritical cycles, since they are more effective in recovering the heat from the hot fluid. This is illustrated by the heat recovery effectiveness $\epsilon$, which is high for the transcritical cycles, while it is low for the subcritical cycles. On the other hand, the subcritical cycles reach higher thermal efficiencies. R134a and R143a are two fluids which are commonly used 
in ORCs; however, R134a is not among the 30 best fluids for either of the two considered hot fluid inlet temperatures, and R143a is only among the 30 highest performing fluids when the hot fluid inlet temperature is $120^{\circ} \mathrm{C}$. For the $120^{\circ} \mathrm{C}$ hot fluid inlet temperature case, R143a is transcritical with a high heat recovery effectiveness and a high thermal efficiency, and is therefore among the high performance fluids. For the $90^{\circ} \mathrm{C}$ hot fluid inlet temperature case, the critical temperature of R143a is too high for efficient transcritical operation, and R143a does therefore obtain best performance when the boiler pressure is subcritical with $\dot{W}_{n}=2.47 \cdot 10^{-2}$. The thermal efficiency of the R143a cycle is still high at $\eta_{I}=6.2 \%$, but the heat recovery effectiveness is reduced to $\epsilon=51.1 \%$, which leads to a large reduction in performance compared to the competing fluids. Considering R134a, a low heat recovery effectiveness is also the reason why this common fluid is not present among the 30 highest performing fluids. For the $120^{\circ} \mathrm{C}$ hot fluid inlet temperature case, the fluid attains $\eta_{I}=9.2 \%$ and $\epsilon=58.7 \%$, and for the $90^{\circ} \mathrm{C}$ hot fluid inlet temperature case, it achieves $\eta_{I}=6.2 \%$ and $\epsilon=48.5 \%$. The thermal efficiency is therefore reasonably high in both cases, but the low heat recovery effectiveness leads to normalized power outputs of $\dot{W}_{n}=4.45 \cdot 10^{-2}$ and $\dot{W}_{n}=2.35 \cdot 10^{-2}$ for the $120^{\circ} \mathrm{C}$ and $90^{\circ} \mathrm{C}$ hot fluid inlet temperature cases, respectively.

\subsection{Critical temperature and temperature glide}

In Fig. 2 the solutions are placed according to their normalized net power output and critical temperature. For both hot fluid inlet temperatures the best solutions are transcritical. For the $120^{\circ} \mathrm{C}$ hot fluid inlet temperature the best solutions have critical temperatures between $60^{\circ} \mathrm{C}$ and $80^{\circ} \mathrm{C}$, and for the $90^{\circ} \mathrm{C}$ hot fluid inlet temperature the critical temperatures are roughly between $40^{\circ} \mathrm{C}$ and $50^{\circ} \mathrm{C}$. For both hot fluid inlet temperatures, the best solutions have critical temperatures around half of the hot fluid inlet temperature.

Usually, the optimum thermodynamic performance is obtained when the temperature glide of condensation, $\Delta T_{g}$, matches the temperature increase of the cooling water, $\Delta T_{\text {cool }}$ $[4,6]$. The results indicate that many of the mixtures have a $\Delta T_{g}$ close to $\Delta T_{\text {cool }}$, but some mixtures have a $\Delta T_{g}$ which is much higher than $\Delta T_{\text {cool }}$. These mixtures have a non-linear temperature glide and are therefore not able to match the temperature profile of the cooling water when $\Delta T_{g} \simeq \Delta T_{\text {cool }}$. A curved condensation temperature profile, in the case where $\Delta T_{g} \simeq \Delta T_{\text {cool }}$, leads to a higher condensation pressure than if the temperature profile is linear. The condensation temperature profile is usually curved when the boiling points of the fluids in the mixture are very different. Figure 3 shows the $\dot{Q} T$-diagrams of condensation for ethane/propane, ethane/heptane and $\mathrm{CO}_{2}$ /propane mixtures optimized for the $120^{\circ} \mathrm{C}$ hot fluid inlet temperature. The $\dot{Q} T$-diagrams for ethane/propane (low boiling point difference) 

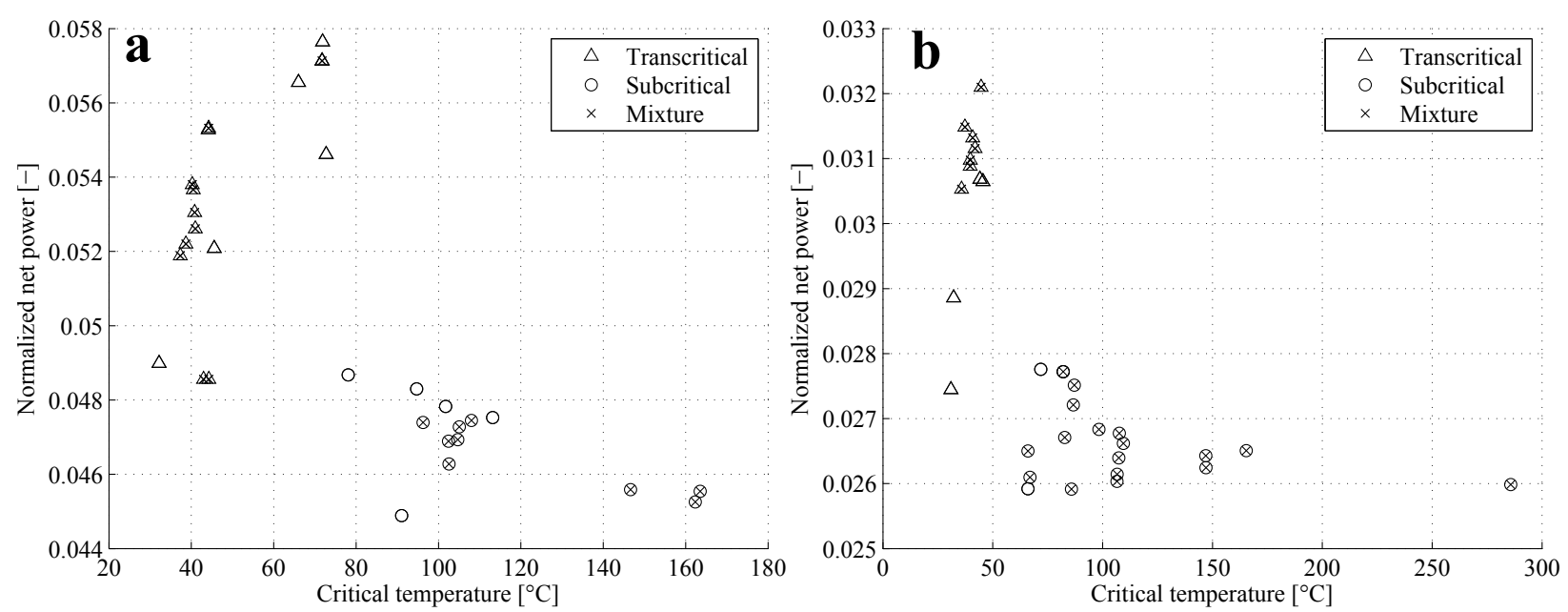

Figure 2: Critical temperature for optimized pure fluids and mixtures for hot fluid inlet temperatures of (a) $T_{h f, i}=120^{\circ} \mathrm{C}$ and (b) $T_{h f, i}=90^{\circ} \mathrm{C}$
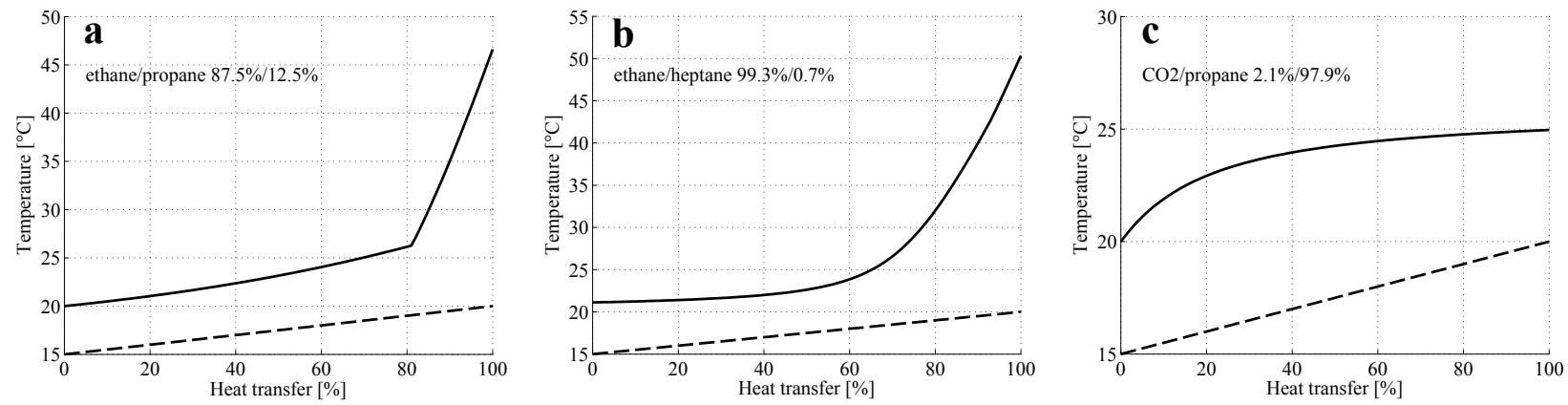

Figure 3: $\dot{Q} T$-diagram for the condenser for (a) ethane/propane, (b) ethane/heptane and (c) CO2/propane for the $120^{\circ} \mathrm{C}$ hot fluid inlet temperature case

and ethane/heptane (high boiling point difference) illustrate how the curvature of the temperature profile affects condensation. Figure 3 (c) shows the $\dot{Q} T$-diagram for $\mathrm{CO}_{2} /$ propane where the temperature profile curves in the opposite direction, thus enabling $\Delta T_{g}=\Delta T_{\text {cool }}$ although the condensation temperature profile is curved. These examples show that the optimum mixture composition is not always found where $\Delta T_{g}=\Delta T_{\text {cool }}$.

For the $90^{\circ} \mathrm{C}$ hot fluid inlet temperature, four mixtures: R32/R125, R125/R143a, R143a/R134a and R125/R134a have temperature glides of condensation below $4^{\circ} \mathrm{C}$. The mixtures achieve these low glides, since the fluids in the mixtures have similar boiling points, and it is therefore not possible for the mixtures to reach higher temperature glides at the given condenser pressures.

The relationship between $\Delta T_{g}$ and $\Delta T_{\text {cool }}$ makes the results dependent on the type of condenser used in the ORC. In the case where the condenser is air-cooled, the temperature 
increase of the cooling flow is larger than $5^{\circ} \mathrm{C}$. Repeating the optimizations with an air-cooled condenser would therefore favor mixtures with higher temperature glides. In this case, other mixture compositions and possibly also other mixtures would be thermodynamically optimal.

\subsection{Turbine parameters}

All fluid candidates, for both of the considered hot fluid inlet temperatures, have turbine enthalpy drops below the limiting value of $65 \mathrm{~kJ} / \mathrm{kg}$, suggesting that a single stage turbine is feasible for all solutions. Considering the volume flow ratio limitation, however, the results suggest that a two stage turbine design must be employed for R218, R422A, R125, R143a, R1234yf, R227ea and $\mathrm{C}_{4} \mathrm{~F}_{10}$ for the $120^{\circ} \mathrm{C}$ hot fluid inlet temperature case, and for heptane/octane for the $90^{\circ} \mathrm{C}$ hot fluid inlet temperature case. In addition to this, these fluids all have a large size parameter and are therefore expected to require more expensive turbines than the other fluids in the tables. The volume flows are generally lower for the $90^{\circ} \mathrm{C}$ hot fluid inlet temperature case, and more fluid candidates are thereby available with single stage turbine designs. For the ethane mixtures, the results indicate that compact and low cost single stage turbines can be used.

\subsection{Heat exchangers}

Figure 4 shows the $\bar{U} A$-values for the boiler and the condenser for all the optimized solutions. For both hot fluid inlet temperatures it is seen that the subcritical cycles with pure working fluids require low $\bar{U} A$-values. For the subcritical mixture cycles the condenser $\bar{U} A$-value requirement increases, while the boiler $\bar{U} A$-value requirement is similar to the subcritical pure fluid ORCs. The transcritical cycles with pure working fluids require an increase in both the $\bar{U} A$-value of the boiler and the condenser compared to the subcritical pure fluid ORCs. The $\bar{U} A$-value increase is largest for the boiler. When comparing the transcritical cycles with pure working fluids to the transcritical cycles with mixtures as working fluids, primarily an increase in the condenser $\bar{U} A$-value for the mixtures is observed.

When considering the $\bar{U} A$-values, only one aspect of the heat exchanger design is taken into account, i.e., the ratio of heat transfer to available temperature difference, relating high heat transfer and low temperature difference to large heat transfer areas. Another important aspect that impacts the heat exchanger size is the heat transfer properties of the working fluid expressed through the $\bar{U}$-value. Thermal conductivity, viscosity and diffusivity (for mixtures) are transport properties which determine the heat transfer performance of a specific fluid. Analysing the effect of the transport properties on the heat exchanger area requires a detailed heat exchanger design analysis, which is out of the scope of this paper. In 

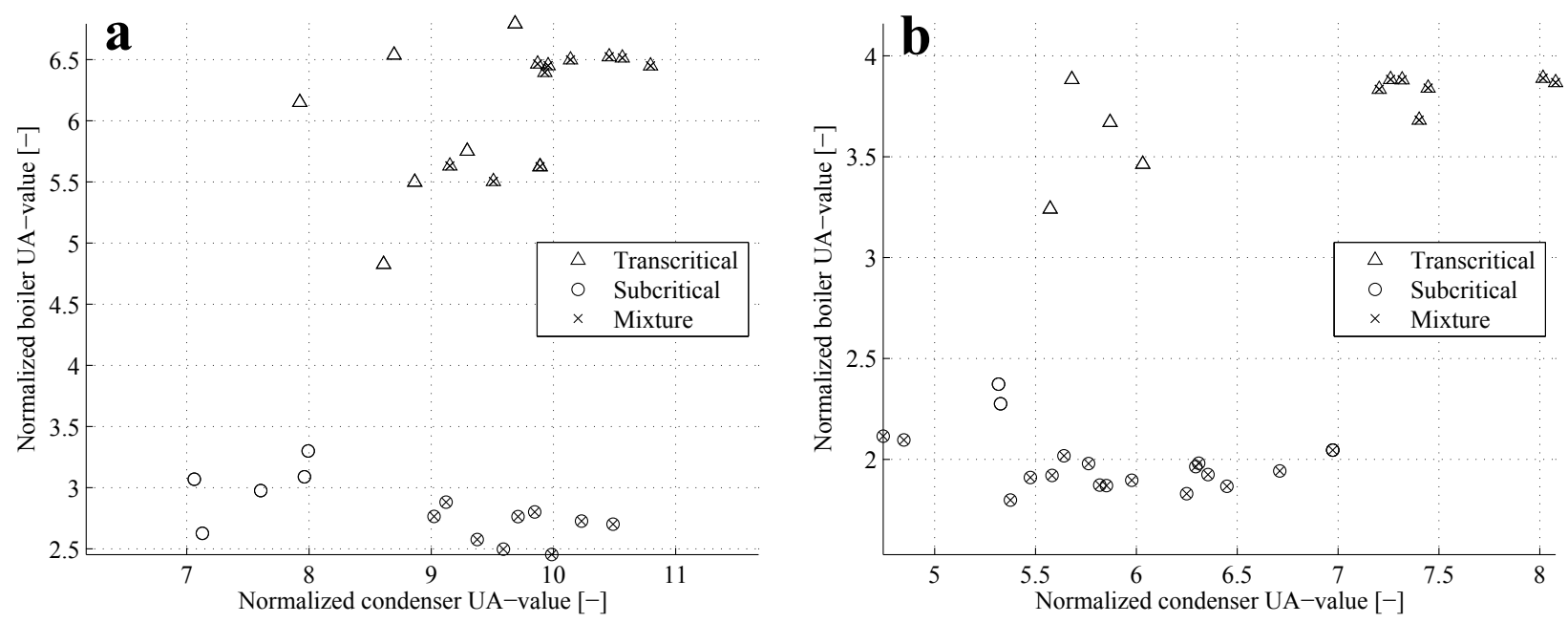

Figure 4: Normalized $\bar{U} A$-values for the condenser and the boiler for optimized pure fluids and mixtures for hot fluid inlet temperatures of (a) $T_{h f, i}=120^{\circ} \mathrm{C}$ and (b) $T_{h f, i}=90^{\circ} \mathrm{C}$

a comparison of pure fluids and mixtures, it is expected that the heat transfer performance of a mixture is worse than the heat transfer performance of the pure fluids in the mixture, due to degradation of transport properties and the phase change process being limited by diffusion [19].

\subsection{Hazards and global warming potential}

The lists of fluids shown in Tables 4 and 5 do not present many solutions where both hazards and GWP are low, since the majority of the fluids have either high flammability (hydrocarbons) or high GWP (refrigerants). $\mathrm{CO}_{2}$ for the $120^{\circ} \mathrm{C}$ hot fluid inlet temperature case and R1234yf for the $90^{\circ} \mathrm{C}$ hot fluid inlet temperature case are the only two solutions that provide the option of low hazards and GWP. Depending on regulations it may be required, for example, to use a non-flammable working fluid, thus eliminating the flammable fluids from the list of considered working fluids. In both optimization cases this requirement means excluding a significant portion of the working fluids. The environmental effect of using a high GWP working fluid is dependent on how the ORC plant is operated and managed, i.e., the procedures used for purging and refilling, and on how likely leakages are to occur.

\section{Discussion}

None of the analysed working fluids achieves optimal performance for all of the considered criteria. The working fluid selection is thus a matter of finding a good compromise between relevant parameters. When mixtures are considered as possible working fluids along with 
pure fluids, the total number of possible working fluids increases dramatically. This is seen in Tables 4 and 5 where 19 and 24 mixtures, respectively, are included among the 30 thermodynamically best fluids for each of the two hot fluid inlet temperature cases, even though many of the highest performing pure fluids are not considered in mixtures. This suggests that a better compromise can be achieved, if mixtures are included in the ORC optimization, than if only pure fluids are considered as working fluids.

For many of the mixtures considered in this paper it is possible to achieve an increased net power output while reducing both the boiler and condensation pressure. This is probably also possible for the fluids, that were excluded as possible fluids in mixtures due to lack of validated models for property data estimation. The results indicate that R218 is a high performance working fluid for low temperature ORCs. If R218 is mixed with another high performance fluid it is possible that the net power output can be further increased, while the pressure levels are reduced. The three-component mixtures, R422A and R419A, do also turn out as high performance fluids although the composition of the mixtures is not optimized. By considering a larger number of three-component mixtures and optimizing the composition, it is likely that even higher net power outputs can be achieved.

The hot fluid chosen for the analysis presented in this paper is typical for geothermal heat sources. By changing the hot fluid from water to air or to a thermal oil, the heat capacity of the incoming heat stream changes. This affects the mass flow of the ORC and the net power output. The same is true for changes in the hot fluid mass flow. When the conditions stated in Section 2.1 are satisfied, the results of the optimizations are unaffected by a change in hot fluid mass flow and heat capacity, and the net power output and $\bar{U} A$ for a given application can be obtained using the normalized values presented in Tables 4 and 5. Considering the design of the components, the mass flow and heat capacity influence the size of the ORC system and have a significant impact on the result of a heat exchanger or expander design analysis. For hot fluid inlet temperatures other than $T_{h f, i}=120^{\circ} \mathrm{C}$ and $T_{h f, i}=90^{\circ} \mathrm{C}$, the presented fluid rankings are not valid, since the hot fluid inlet temperature has an important influence on which fluid is optimal. In some ORC applications it is necessary to limit the hot fluid outlet temperature. This also influences the results of the optimizations, and the presented fluid rankings are therefore not valid when such a temperature limitation applies.

The ranking of the fluids in Tables 4 and 5 is based on the optimized net power outputs which are quite close for some fluids. When this is the case, inaccuracies in the optimization and the fluid property data might affect the fluid rankings. Since it is not possible to convert directly the reported uncertainties in density, speed of sound and heat capacity of the fluid 
property data models [8-10] to uncertainties in e.g. enthalpy and entropy, it is out of the scope of this paper to estimate quantitatively the impact of the fluid property data errors on the net power outputs. The highest uncertainties are however below 5\%, so a large impact on the results is not expected. The fluids in the top of the tables will most likely remain high performance fluids also when these inaccuracies are taking into account; however, they might shift position with fluids that reach similar net power outputs.

\subsection{Comparison with the literature}

The modeling conditions used by Heberle et al. [4] have many similarities with the modeling conditions used in this paper. In both studies there is no limit on the boiler outlet temperature, and both studies use the same fixed temperature increase of the cooling water. Heberle et al. [4] carried out optimizations for mole fractions ranging from 0 to 1 in steps of 0.1 for a recuperated ORC, i.e., 11 different mole compositions were optimized. The optimum mole composition for the isobutane/isopentane mixture was found as $(0.9 / 0.1)$ by Heberle et al. [4] and as $(0.82 / 0.18)$ in this paper. The difference is caused by differences in the boiler pinch point, differences in the definition of the turbine inlet state and the use of different versions of fluid property models. For both optimizations the optimum is found close to the point where the temperature glide of condensation matches the temperature increase of the cooling water. For the $120^{\circ} \mathrm{C}$ hot fluid inlet temperature case, the analysis of this paper indicates that an even higher net power output can be achieved if isobutane is mixed with either propane, $\mathrm{CO}_{2}$ or ethane or if isopentane is mixed with propane or ethane. For the $90^{\circ} \mathrm{C}$ hot fluid inlet temperature a higher net power output can be achieved if isobutane is mixed with ethane or propane and if isopentane is mixed with ethane or butane. The pressure levels in the ethane, $\mathrm{CO}_{2}$ and propane mixture cycles are however significantly higher than the pressure levels in the isobutane/isopentane mixture cycle. Comparing the mixtures isobutane/isopentane and butane/isopentane for the $90^{\circ} \mathrm{C}$ hot fluid inlet temperature, one sees that the two mixtures reach similar net power outputs, turbine volume flow ratios, total $\bar{U} A$-value, hazard level and GWP, while the pressure levels are lower for the butane/isopentane mixture. This indicates that it is preferable to mix isopentane with butane instead of isobutane for the $90^{\circ} \mathrm{C}$ hot fluid inlet temperature.

Larsen et al. [20] recently presented multiple regression models for prediction of the maximum obtainable thermal efficiency of recuperated and non-recuperated ORCs. For hot fluid inlet temperatures between 80 and $180^{\circ} \mathrm{C}$, the thermal efficiency can be calculated from the hot fluid inlet temperature, the hot fluid outlet temperature and the polytropic efficiency of the turbine (assuming fixed condensation temperature $T_{\text {cond }}=25^{\circ} \mathrm{C}$ and fixed 
heat exchanger pinch points $\Delta T_{p p}=5^{\circ} \mathrm{C}$ ). Considering pure fluids, R218 and R125 reach the highest net power outputs for the $120^{\circ} \mathrm{C}$ hot fluid inlet temperature optimization, with hot fluid outlet temperatures of 40.7 and $45.9^{\circ} \mathrm{C}$, respectively. The thermal efficiencies estimated with the multiple regression model developed by Larsen et al. [20] agree with the thermal efficiencies calculated in this paper within $2.5 \%$ for these two fluids. This is a very good correspondence considering that the condensation temperature, the boiler pinch point and the hot fluid outlet temperature are out of the validity range given by Larsen et al. [20].

\section{Conclusion}

This paper presents a generic method for simultaneous fluid selection and optimization of ORCs considering pure fluids, predefined mixtures and binary optimized working fluids. The results obtained by implementing the proposed method to optimize ORCs for two low temperature heat sources with inlet temperatures at $120^{\circ} \mathrm{C}$ and $90^{\circ} \mathrm{C}$ suggest that the solution space is significantly increased when mixtures are included as possible working fluids. Even with a limitation on the fluids considered in mixtures, it is found that 19 of the 30 thermodynamically best fluids are mixtures for the $120^{\circ} \mathrm{C}$ hot fluid inlet temperature optimization, while 24 mixtures are found for the $90^{\circ} \mathrm{C}$ hot fluid inlet temperature optimization. The transcritical cycles achieve the highest net power outputs, and the highest performing transcritical cycles have working fluids with critical temperatures around half of the hot fluid inlet temperature. For the $120^{\circ} \mathrm{C}$ hot fluid inlet temperature case, R218 achieves the highest net power output. None of the mixtures analysed in this paper is able to compete with this, but if mixtures containing R218 are included in the optimization, higher net power outputs can possibly be reached. A mixture of propane and ethane is found to achieve high net power outputs for both hot fluid inlet temperature cases. Compared to pure ethane, the net power output is increased by $12.9 \%$ for the $120^{\circ} \mathrm{C}$ hot fluid inlet temperature case and $11.1 \%$ for the $90^{\circ} \mathrm{C}$ hot fluid inlet temperature case.

\section{References}

[1] B. Tchanche, G. Lambrinos, A. Frangoudakis, G. Papadakis, Low-grade heat conversion into power using organic Rankine cycles - A review of various applications, Renew Sust Energ Rev 15 (2011) 3963-79. doi:dx.doi.org/10.1016/j.rser.2011.07.024.

[2] J. Bao, L. Zhao, A review of working fluid and expander selections for organic Rankine cycle, Renew Sust Energ Rev 24 (2013) 325-42. doi:dx.doi.org/10.1016/j.rser.2013.03.040.

[3] G. Angelino, P. Colonna, Multicomponent working fluids for organic Rankine cycles (ORCs), Energy 23 (1998) 449-63. doi:dx.doi.org/10.1016/S0360-5442(98)00009-7. 
[4] F. Heberle, M. Preißinger, D. Brüggemann, Zeotropic mixtures as working fluids in Organic Rankine Cycles for low-enthalpy geothermal resources, Renew Energ 37 (2012) 364-70. doi:dx.doi.org/10.1016/j.renene.2011.06.044.

[5] C. Trapp, P. Colonna, Efficiency Improvement in Precombustion $\mathrm{CO}_{2}$ Removal Units With a Waste-Heat Recovery ORC Power Plant, J Eng Gas Turb Power 135 (2013) 042311 (12 pages). doi:dx.doi.org/10.1115/1.4023121.

[6] M. Chys, M. van den Broek, B. Vanslambrouck, M. D. Paepe, Potential of zeotropic mixtures as working fluids in organic Rankine cycles, Energy 44 (2012) 623-32. doi:dx.doi.org/10.1016/j.energy.2012.05.030.

[7] A. Papadopoulos, M. Stijepovic, P. Linke, P. Seferlis, S. Voutetakis, Toward Optimum Working Fluid Mixtures for Organic Rankine Cycles using Molecular Design and Sensitivity Analysis, Ind. Eng. Chem. Res. 52 (2013) 12116-33. doi:dx.doi.org/10.1021/ie400968j.

[8] E. Lemmon, M. Huber, M. McLinden, NIST Standard Reference Database 23: Reference Fluid Thermodynamic and Transport Properties-REFPROP, Version 9.0, National Institute of Standards and Technology, Standard Reference Data Program, Gaithersburg, 2010, www.nist.gov.

[9] E. Lemmon, R. Jacobsen, Equations of State for Mixtures of R-32, R-125, R-134a, R-143a and R-152a, J. Phys. Chem. Ref. Data vol. 33 (2) (2004) 593-620. doi:dx.doi.org/10.1063/1.1649997.

[10] O. Kunz, W. Wagner, The GERG-2008 Wide-Range Equation of State for Natural Gases and Other Mixtures: An Expansion of GERG-2004, J. Chem. Eng. Data vol. 57 (2012) 3032-91. doi:dx.doi.org/10.1021/je300655b.

[11] E. Macchi, A. Perdichizzi, Efficiency Prediction for Axial-Flow Turbines Operating with Nonconventional Fluids, J Eng Power-T ASME 103 (1981) 718-24. doi:dx.doi.org/10.1115/1.3230794.

[12] M. Astolfi, M. C. Romano, P. Bombarda, E. Macchi, Binary ORC (Organic Rankine Cycles) power plants for the exploitation of medium-low temperature geothermal sources - Part B: Techno-economic optimization, Energy 66 (2014) 435-46. doi:dx.doi.org/10.1016/j.energy.2013.11.057.

[13] American Coatings Association, Hazardous Materials Identification System (May 2014). URL www . paint .org/publications/labeling.html

[14] W. Collins, R. Derwent, C. Johnson, D. Stevenson, The oxidation of organic compounds in the troposphere and their global warming potentials, Climatic Change 52 (4) (2002) 453-479. doi:dx.doi.org/10.1023/A:1014221225434.

[15] Solomon, S. and Qin, D. and Manning, M. and Chen, Z. and Marquis, M. and Averyt, K.B. and Tignor, M. and Miller, H.L., IPCC Fourth Assessment Report: Climate Change 2007 (AR4), Tech. rep., Intergovernmental panel on climate change (2007).

[16] MathWorks Inc., Documentation for the matlab function ga, www.mathworks.se/help/gads/gaoptimset.html (May 2014).

[17] D. Walraven, B. Laenen, W. D'haeseleer, Comparison of thermodynamic cycles for power production from low-temperature geothermal heat sources, Energy Convers Manage 66 (2013) 2-14. doi:dx.doi.org/10.1016/j.enconman.2012.10.003.

[18] U. Larsen, L. Pierobon, F. Haglind, C. Gebrielii, Design and optimisation of organic Rankine cycles for waste heat recovery in marine applications using the principles of natural selection, Energy 55 (2013) 803-12. doi:dx.doi.org/10.1016/j.energy.2013.03.021.

[19] R. Radermacher, Thermodynamic and heat transfer implications of working fluid mixtures in Rankine 
cycles, Int. J. Heat and Fluid Flow 10 (2) (1989) 90-102. doi:dx.doi.org/10.1016/0142-727X(89)90001-5.

[20] U. Larsen, L. Pierobon, J. Wronski, F. Haglind, Multiple regression models for the prediction of the maximum obtainable thermal efficiency of organic Rankine cycles, Energy 65 (2014) 503-10. doi:dx.doi.org/10.1016/j.energy.2013.10.026. 